\title{
DUEÑOS DE UNA NOCHE DE VERANO: SOBRE ENERO DE SARA GALLARDO
}

\section{Owners of a summer night: About Enero by Sara Gallardo}

\author{
Marcelo Méndez* \\ Universidad de Buenos Aires \\ marcelomendezlor@gmail.com
}

Palabras clave

campo;

violación;

embarazo;

aborto;

poder

Keywords

country;

rape;

pregnancy;

abortion;

power

\section{Resumen}

En las aguas poco turbulentas del campo literario argentino de 1958, la aparición de Enero, primera novela de Sara Gallardo, significó una irrupción notable. Habría que empezar diciendo que el modo a la vez lacónico y violento con el que Gallardo dota al campo en esta novela incide fuertemente en su desarrollo.

Coherentemente con esto, hay que decir que, a los personajes de la novela, puesteros pobres en una estancia, no les faltan los problemas: Nefer, la joven adolescente que protagoniza el texto, ha sido violada y no termina de decidirse a abortar. El relato de la violación, que se vale de continuadas metonimias, es un gran momento de la prosa de Gallardo, mientras que todo el periplo que se dibuja alrededor de la voluntad de abortar de Nefer (su cabalgata a lo de la "Bruja Borges", su temor, los parientes que utiliza como excusa), da pie a una guía práctica sobre el aborto.

Finalmente, el deseo de Nefer sucumbe a tres poderes concéntricos (Enero es también una novela sobre el poder): el que representa su madre, el que detenta la Iglesia y el que pone en juego la dueña de la estancia.

\begin{abstract}
When it was published, in 1958, Sara Gallardo's Enero was a great irruption in argentine literature. The laconic and as well violente way that Gallardo uses to write about the country -against a strong tradition that put it as a wonderful place came like a fresh new to this literature.

The characters that live in Gallardo's country have many troubles. Nefer, the main character of the novel, has been raped in a party, in lines where the writing of Gallardo, specially its use of metonymy is very brilliant, and she is actually pregnant. Her long way over her friendly horse to look for the woman that use to make the abortions, a secret that everybody over that land knows, is a great moment in Gallardo's literature.

Finnally, Nefer don't have her abortion. She is under the rude power of his mother, the church, and the owner of the land. Enero is also a novel about power. They arranged the marriage of Nefer whit the man that had raped her. Justice on this country its very peculiar. However, a strong literature becames from that unfair world.
\end{abstract}




\section{Dueños de una noche de verano: sobre Enero de Sara Gallardo}

Sara Gallardo publicó Enero, su primera novela, en 1958. Ayuda a situarse en aquel entonces pensar que ese año los militares de la autodenominada Revolución Libertadora le tuvieron que entregar la presidencia a Arturo Frondizi, que había sido resultado electo. Juan Perón, aislado en República Dominicana, todavía no imaginaba que su exilio duraría 18 años. Tampoco River Plate, campeón en el 57, pensaba que le llevaría esa misma cantidad de tiempo volver a ganar un campeonato de fútbol, excluyentemente masculino hasta hace bien poco. En 1958, la cultura rock ya había aparecido con gran fuerza en Estados Unidos, llamando la atención de los músicos ingleses, pero en la Argentina, donde el tango iba cuesta abajo y el folklore no había dado aún su gran salto, todavía no había rock nacional. La industria cultural eran la radio y el cine. Borges había escrito ya lo mejor de su producción, Julio Cortázar no pasaba por esos días de ser un promisorio escritor de cuentos, mientras que el realismo, de la mano de David Viñas y de algunos escritores ligados al Partido Comunista -Andrés Rivera, Bernardo Verbitsky, Juan José Manauta- atravesaba un buen momento. Tres escritoras, Beatriz Guido, Silvina Bullrich y Martha Lynch despuntaban la popularidad inmensa que luego tuvieron, merecedora de mayor estudio. Son solo grandes rasgos, pero insinúan un país de tranco corto, a medio camino entre un primer peronismo que había terminado y unos años sesenta que tardaban en llegar. Un país al que no le vienen mal aquellas precisas palabras de Antonio Gramsci: "Il vecchio muore e il nuevo non può nasceré: in questo interregno si verificano i fenomini morbosi più svarati" (Gramsci, 1977, p. 66) Son, en suma, los años signados por Los muchos que no viven, la novela de Alberto Vanasco (1967), que hace tándem con Los jóvenes viejos (1962), la película de Rodolfo Kuhn, portadoras ambas de una estética del vacío existencial y político que encontraba entonces por donde desplegarse.

Conviene no perder de vista este racconto porque señala la transgresora novedad del texto con que se inicia la obra de Sara Gallardo. Publicada en el seno de esa sociedad, a contrapelo de sus expectativas y convenciones, Enero representa una verdadera irrupción en la cultura argentina y en el sistema literario nacional. No tanto por el volumen de sus ventas, claro está, aspecto donde sacaba ventaja el trío de escritoras mencionado más arriba, pero sí por la forma innovadora -en rigor habría que decir anticipatoria, futura- en que presenta la temática del aborto y los andares de una chica tímida que carga por el campo con un embarazo no deseado. Importa destacar que ese vínculo entre campo y protagonista es puntualmente aquel con el que Lucía De Leone caracterizó la obra de Gallardo, quien de acuerdo con su lectura "realiza un desvío en la construcción del punto de vista narrativo respecto de la tradición en que se inscribe" (2009, p. 116). Gallardo supera de esta forma dos barreras: la que representa la moral conservadora de esa sociedad, que a menudo se anclaba en su espacio rural y, ya en el sistema literario, la que el pudor borgeano (Pauls, 2004, p. 43) imponía a la hora de sugerir el límite de lo decible en la literatura argentina de esos años. Cabe agregar que la novela, saludada por María Elena Walsh y María Rosa Oliver en revistas importantes de la época, prontamente reeditada por Sudamericana, fue traducida al alemán y al checo, lenguas a las que la literatura argentina no accede con frecuencia. 
Enero ya había tenido una importante recepción en 2004, cuando Leopoldo Brizuela edita la Narrativa breve completa de Gallardo. Y cuando se la reedita en 2018, el texto se vincula con naturalidad, así parecieron entenderlo tantos nuevos lectores, al clima de época que tiene uno de sus tópicos centrales en la lucha por el aborto legal, seguro y gratuito. Una conclusión capital de su protagonista: "los patrones y la policía tienen ideas parecidas" señala a los que se adueñarán de su destino a partir de la noche en que sufre una violación. Solo hay que poner "familia" donde Nefer dice policía. La reedición de esta novela es, de alguna manera, una contribución más que pertinente a la victoria gestada por las grandes marchas de mujeres por las calles y plazas de las ciudades argentinas.

Nefer, la protagonista de Enero, ya está embarazada cuando empieza la novela. Su familia de humildes puesteros de estancia, ha recibido a unos comerciantes de origen árabe. El texto deja entender que, aunque son todos de suma confianza, el planteo de un tema difícil no está habilitado y Nefer calla su embarazo. En realidad, lo que le está sucediendo le resulta casi inconcebible, como muestra en un pensamiento que es réplica muda de una conversación rutinaria ("hablan de la cosecha y no saben que para entonces ya no habrá remedio (...) todos los que están aquí, y muchos más, van a saberlo y nadie dejará de hablar" [Gallardo, 2018, p. 9]). La presentación de la protagonista que hace Gallardo anticipa la forma un tanto errática en que Nefer hará frente a este embarazo no deseado a lo largo de toda la novela. Su rebeldía, que está bien presente, se desorganiza al toparse con el marco cultural que supone la estancia. Es una rebeldía que se hace notar a través de enviones cortos que no llegan a articularse entre sí de modo que se vuelva efectiva. La Nefer contestataria se da a conocer en esbozos narrativos que sucumben frente a la ideología reaccionaria que parece formar parte del aire en el campo y los poblados por donde la escritura de Gallardo conduce al lector. José Amícola consideró feudales, palabra que hoy, desviada un poco de su uso más preciso, condensa la injusticia de todo régimen (pre)capitalista (Amícola, 2013, p. 48) a las relaciones sociales en la novela. En efecto, los estancieros y sus sirvientes, los propios familiares de Nefer, se hacen dueños del ultraje que ella sufre en una triste noche estival. Ellos manejan el hecho -no lo abortan- y le imponen sus maniobras "compensatorias".

Cómo sea, la contemporaneidad de Nefer, esa que permite el salto del personaje desde mediados del siglo pasado hasta nuestro más estricto presente, reside en su sorda rebelión a un embarazo que no desea, a un embarazo producto de una violación. Nada de esto sale a la luz con facilidad: el texto estetiza una laboriosa suelta de datos para ver las cosas de cerca.

Nefer vive con su hermana Alcira, a la que la familia ha ungido como niña bonita, con su madre autoritaria y su padre retraído. Habitan un puesto de los tantos que se pueden encontrar en una estancia. Ella, que pasa las madrugadas ordeñando en el tambo, se ocupa también de las tareas domésticas con Alcira y su madre. A la vez, no está de más mencionarlo porque tendrá cierta incidencia en el argumento, Nefer cabalga como nadie. Aunque por más que una cabalgata puntual vaya a resultar significativa, la habilidad sobre el caballo parece propia de una feliz Nefer niña que el presente de la enunciación desmiente. Es que a esa vida que transcurría como tantas se ha sumado ahora "una marea angustiosa [que] la inunda con la realidad de su desgracia" (2018, p. 30). 
Los prejuicios del pueblo-feudo, que no son la menor de las preocupaciones de Nefer, dibujan una constelación de intenciones aviesas de las que es muy difícil escurrirse. Bastaría mencionar que a la condena que pesa sobre la mujer soltera se le suma -o mejor se complementa con ella- la demanda de que la mujer que se casa se embarace pronto, único medio de evitar la sospecha en que queda envuelta si pasado cierto plazo que la sociedad tácitamente consensúa eso no ocurre: "tres meses que se casó, ya podría haber novedades, eh" (2018, p. 22), sentencia la dueña de la estancia refiriéndose a poco de empezar la novela, aclarando así los tantos, a alguien que está bajo su órbita.

Pero esta dialéctica que alcanza a casi todo el universo femenino se vuelve apenas una instancia desagradable si se compara con el modo con que los pobladores pueden apañar y naturalizar abusos sexuales y violaciones.

El caso de Nefer, que resulta violada en el casamiento de su hermana la Porota, presentado en el texto como una "seducción seguida de abuso sexual" (Laera, 2018), resulta clave también para el argumento de la novela. El carácter metonímico que asume allí la narración de Gallardo es sutil sin dejar por eso de ser violento.

Pero antes, y es importante consignarlo porque Gallardo parece reconocerle alguna relación con el ataque sexual, hay que pensar en el vano amor de Nefer por el Negro, comprometido con la elegante Delia. Es esta, la historia de amor que Nefer querría tener con el Negro, una segunda historia, necesaria y siempre subalterna que opera por debajo de la cara dominante del relato (Piglia, 2014, p. 103).

La vulnerabilidad de Nefer se acrecienta en el casamiento de Porota, que es en la práctica un baile donde todos beben demasiado. Capturada su atención por el esquivo amor del Negro hacia ella, a Nefer le cuesta notar que Nicolás se propone atacarla. Incluso más adelante, en una lectura sobre la que habrá que volver, ella lo acusa en forma oblicua: "y era su culpa, era culpa del Negro, porque ella ni sabía cómo había sido, pero era culpa del Negro" (2018, p. 12). En términos de Alejandra Laera, Nefer se enoja con "el Negro por ser quien suscita su deseo", del que se culpabiliza (2018, párr. 3). No parece ser así: Gallardo señala al violador con un par de alusiones: "la toma por un brazo y las espinas del monte se incrustan en su espalda" (2018, p. 16) es la más eficaz. La fuerza que se ejerce sobre el brazo y la presencia metonímica de las espinas indican la violencia y la pérdida de control de la víctima, que en condiciones normales está más cerca de ser una baqueana que una chica que pueda bandearse, irse sola contra el monte. Nicolás, que pasa a ser "el hombre" (2018, p. 18), en un significativo desplazamiento de la escritura, "tiene bigotes y olor a vino, hace calor, las ramas de los árboles son un mundo, el Negro está con Delia, el hombre suda” (2018, p. 16).

Los reconocimientos que ha merecido la prosa de Gallardo responden a tantísimos pasajes de su obra, pero bien ganados estarían de cara a los finos desplazamientos con que la autora resuelve la situación clave de la novela: la violación. Nada indica que la violación no pueda narrarse de manera más directa. Por poner un caso emblemático y pocas veces señalado, las cuatro novelas de Julio Cortázar, que algunos años después de la publicación de esta novela de Gallardo devendría autor faro, relatan de manera cruda y directa escenas de sexo no consentido. Se destaca, por su violencia, la violación del adolescente hacia el final de Los Premios (1960), y por la sordidez de un lenguaje 
pretendidamente poético, el abuso de Oliveira sobre La Maga en el capítulo 5 de Rayuela (1963). Este último caso, a través de personajes no tan recordados, se reedita en 62 Modelo para armar (1968), violación de Celia por Helene y Libro de Manuel (1973), violación de Ludmila por Andrés. Pero lo cierto es que Gallardo por fidelidad a su estilo, por un amoroso cuidado de la figura de Nefer y, en cierta medida, por imposición de la época, se apoya en la metonimia y su versión parece inmejorable: poco dice, pero nada escamotea. De manera que el violador es el que el texto ya condena cuando lo designa como personaje sudoroso, evidencia epidérmica, sinécdoque del crimen que Gallardo sugiere y esto es así aunque Nefer nunca quite su atención de la pareja envidiada del pueblo, la del Negro y Delia. El embarazo que tanto rechaza Nefer y que además la pone ante el problema de alterar la vida sencilla de mucha gente, lo que para ella no es poca cosa, arrastra este origen criminal.

Crimen este que no es ajeno a las más rudas costumbres del pueblo donde la familia de Nefer alterna con gente considerada importante, por quienes muestra un respeto servil, y otros a los que piensa por debajo de ellos, suerte de descastados a los que se debe evitar de cualquier modo. Entre los personajes que están cerca de Néfer se encuentra la señora algo misteriosa que practica abortos clandestinos y que tendrá su lugar en la trama ideada por Gallardo.

Si las diferentes formas del acoso sexual sobre las mujeres son el infierno silenciado de este pueblo, no se deben perder de vista ciertas costumbres que se le vinculan y que delatan que se ha generado un espacio que promueve la sumisión femenina. Es que, así como la violencia explícita concita siempre la atención inmediata y subsiguiente condena, no es ocioso considerar la importancia del control ideológico que domina a la población de un modo casi tangible, que en esta primera enseñanza campera que da Gallardo, una impugnadora de las figuraciones habituales de lo rural en literatura. La ley de la estancia mantiene vigente la posibilidad de que los machistas del lugar cuenten con impunidad para sus actos violentos.

Si se atiende a cuestiones supuestamente menores, podrá decirse que nada en esta novela permite constatar la vigencia de esta ideología dominante, como la mirada baja que adoptan las mujeres trabajadoras del pueblo cada vez que tienen un varón enfrente, un factor en el que Gallardo insiste hasta dotarlo de una fuerte significación. En cada encuentro que propicia la novela la mirada femenina se dirige hacia abajo. La cabeza gacha es el corolario atento a las relaciones de poder de ese gesto La experiencia de generaciones pretéritas le desaconsejan mirar a los ojos, resignándose a ocupar la parte baja de una relación de poder regida por los hombres. "Y después le ofreció el mate con los ojos bajos" (2018, p. 14), por dar un ejemplo, aparece como una frase emblemática, ya que si no se mira a quien se le pasa el mate, este toma carácter de ofrenda, extraviada la virtuosa democracia de la ronda, pero en realidad hay todo un conjunto de sintagmas que va tejiendo un modo de subordinación. Aquí hay algunos: "tal vez se le nota en los ojos, fijos en las alpargatas" (2018, p. 20), "Nefer quisiera permanecer en el banco con los ojos cerrados" (2018, p. 65), "bajando la cara mira los zapatos vencidos de Doña María” (2018, p. 82), "Siente que sus ojos no podrán volver a levantarse (2018, p. 82). También resulta pertinente citar el temor que impulsa el descenso de esas miradas, cuando se dice: "tal vez vaya y le cuente a los ricos de la estancia y luego la miren todos". Bajar la mirada y a la vez ser 
mirada por todos, es la acabada asimetría y la sinécdoque de un estado de la cuestión. El de la imposición patriarcal en el pueblo innominado de la novela.

Como un suplemento que se agrega a la fuerte dominación masculina por la que las chicas del lugar, particularmente las hijas de los puesteros o cualquier otra de posición humilde -porque hay aquí también en juego una cuestión de clase-, se habitúan a bajar la mirada ante los hombres (los hombres y las estancieras), opera el particular saludo que Nefer y su hermana Alcira han vuelto un apotegma fijo, impedido de toda innovación: "bieniusté", así saludan. Bieniusté, todo junto, apretado, casi como si se valieran de una palabra inventada para contestar a todo aquel que quiere acercarse a ellas.

La contracción parece tener por primer objetivo reducir la experiencia personal de las jóvenes, ya que al "bien" se le pega un apurado "y usted" que devuelve la atención como un frontón sobre quien formula la pregunta o (pregunta con la fórmula), sin dar detalles sobre la situación de ellas. Devuelve la atención sobre la persona "importante" que condesciende a preguntar por Nefer y su hermana. Pero hay una segunda lectura de esto: la forma final que adquiere la tercera sílaba de su estudiado saludo funciona como un parapeto a toda intención de quien pregunta por llegar más allá del saludo con alguna de ellas. Es una modalidad del "usted" con potencias de clausura, que recuerda, de manera microscópica, los vientos políticos del "no pasarán”. El otro comprende que la conversación ha terminado, pero lo más grave es que debe terminar ya que ni Nefer, ni Alcira ni ninguna de su condición debe entreverarse en un diálogo con esos hombres más -o menos- distinguidos. Por el reverso de esta abstención forzada, también se explica la violencia oculta que se mencionó más arriba. Puntualmente, el "bieniusté" es también para Nefer un escudo que preserva su condición de embarazada reciente. En suma, la boca y los ojos de estas jóvenes de acendrada ruralidad ponen metonímicamente el acento sobre sus vidas difíciles.

Puesta en una situación difícil, Nefer no va a quedarse quieta. Perece haber tomado la decisión de abortar. La vieja Borges que vive en la otra punta del pueblo puede ocuparse. Digresivamente, cabe señalar que el manejo irreverente del apellido Borges no deja de indicar la confianza de Gallardo en su propia escritura y la autonomía con que la desarrolla en el sistema de la literatura argentina.

Nefer galopa hasta allí. Sortea la injuriosa guardia de los hermanos Borges, que algo tienen de los hermanos de "La Intrusa” - "A caballo hay que andar cuando se es puta, cuando se es puta, puta y reputa, a caballo, sî” (2018, p. 39)-, insinuando que el galope conspira contra el embarazo. Un tío, que es su vecino, le sirve de coartada ("siglos de astucia cuajan en Nefer y salen sosteniendo sus palabras, mientras siente en las piernas el jadeo del tordillo" [2018, p. 37]). Y "me voy a llegar allá, a lo de Borges, así doy el aviso y me refresco un poco antes de volver" (2018, p. 37), dice a los tíos. Como se verá, no los engaña.

Pero ante la vieja Borges, "la mujer es gorda y la voz se descarrila a clarinazos" $(2018,39)$, según establece el logrado tono de Gallardo al presentarla, Nefer flaquea. ¿No querés nada de mí? ¿No quisieras algo...? ¿Alguna cosa? (2018, p. 42), presiona la bruja. "Una corriente sube en Nefer y antes que sepa qué contestar dice: yo señora...no gracias...no” (2018, p. 42) En esta paradójica instancia que es el "decir antes de contestar" atropella la súbita negativa de Nefer. Negativa a abortar, negativa 
a hacerlo en manos de esa mujer, eso no se especifica. Son secretos que Nefer se lleva a caballo, donde “se siente casi en casa” (2018, p. 42).

La cuestión del aborto devela así su estado en la novela de Gallardo, donde a juicio de Alejandra Laera aparece como "la pura clandestinidad" (2018). La decisión de la mujer, que hoy se halla en el centro de las argumentaciones del flamante paradigma de la cultura, y cuya indudable primacía articula un nuevo sentido común, en el caso de Nefer todavía debe transitar por el espacio estriado, vinculado por Deleuze y Guattari a los aparatos de captura (Deleuze, 2006, p. 345), que ponen al paso la cultura y el Estado de su tiempo. El aborto, como el embarazo extramatrimonial son tabúes para el lenguaje de ese pueblo. Nefer se decide a abortar pero, obligada por ahora a preservar el secreto que guarda una familia donde se hablará de todo menos de su embarazo, se enfrenta a una cabalgata a la hora de mayor calor. Hora secreta -la siesta- en la que si disminuye la actividad en cualquier calle de barrio, en el pueblo de la novela se produce una verdadera banda negativa. Asimismo, debe mentirles a sus tíos, que la reciben afectuosos pero extrañados en la tarde calurosa, enfrentarse a los rústicos hijos de la bruja, personajes de evidente formación patriarcal que le enrostran malamente su propósito (aunque de eso viven). Por último, llega al careo con la bruja, un emblema de clandestinidad a los ojos de la adolescente. La decisión, en el texto, no atraviesa todo eso sin revertirse. Nefer no abortará. Se le reserva un futuro cruel.

Este tramo de la novela que problematiza el tema del aborto y a modo de excepción frente a lo que se afirmó al comienzo, tributa, aunque con un claro sesgo de avanzada, de tensión hacia el futuro, a la situación que regía al momento de su publicación. La acepción religiosa de "vida" con la que no dejan de martillar las iglesias impregna el accionar de los personajes.

En este sentido, resulta interesante cotejar las idas y vueltas de Nefer, que plantea la trama, con el notable artículo de Ilona Aczel que la lee así: "atrapada en el silencio impuesto por el pánico a que se descubra su embarazo, fruto de una violación que, al deshonrarla, no puede denunciar ni comunicar" (2020, p. 480). En el mismo sentido, Aczel se explaya sobre el lugar que se le da al honor en todo esto: "A través del dipositivo del honor, entonces, la sociedad disciplina la sexualidad femenina al criminalizarla: volviéndola un peligro para la portadora y sus allegades, legitima su control y obliga a su vigilancia” (2020, p. 478).

Desde este planteo resulta evidente que Nefer, que para algo galopó sin parar en esa siesta tórrida está claramente decidida a no dar vida pero no se atreve a lo que en última instancia considera dar muerte. Es ella la que se encuentra ante un límite. Parada en una encrucijada de caminos desgraciados. Con todo, Nefer no delega en nadie su trabajosa decisión, pero esta decisión varía, desvaría, entre la bruja y los varones hostiles que la hostigan. En suma, Nefer se empantana.

De ninguna manera el texto de Gallardo clausura la posibilidad de la que la muerte que por momentos Nefer parece entrever, sea la propia, puesta como está, en manos de una curandera improvisada, de una persona -la tal Borges, apellido que sugiere cuchillos "que acaso no sabrá manejar" (1995, p. 205)- de la que, si no media un embarazo indeseado, todos toman distancia. Se 
trata de un factor que el texto apenas sugiere pero que su lectura en el presente pone fuertemente en juego: la muerte de mujeres por abortos clandestinos.

Fuera de toda duda esta es la zona de la novela que se abre a los debates actuales, que se vuelcan de forma retrospectiva sobre la desafortunada Nefer. Mabel Campagnoli pone sobre la mesa que la biopolítica interrumpe los puentes entre vida y derecho y propone rescatar una mirada sobre el aborto que rescate sus dimensiones eróticas y sexuales (2019, p. 190). De forma concomitante Andrea Lacombe (2012, p. 152), destaca que la lucha por el aborto libre seguro y gratuito es una lucha por una exclusión: ser excluidas y excluidos de la reproducción. Dos tomas de posición que producen sentido: la del aborto como monstruo, en tanto singularización absoluta, según la certera definición de César Aira (1993, p. 17), pero monstruo que esta vez porta una intención positiva, el que representa un cúmulo de nuevos sujetos. Bajo el sol calcinante de la siesta en el campo, Nefer se lee hoy atravesada por este tejido de conceptos.

La pulseada que sostiene Nefer con su deseo, su calor y los conocidos dispuestos a prejuzgarla, se resuelve en contra de la realización del aborto. Con economía narrativa se da paso entonces al momento en que su embarazo se vuelve un tema familiar, en páginas en las que Gallardo parece inventar una especie de grotesco rural, que tal vez opere como otra manera de dotar al campo de nuevos ojos, para usar la fórmula propuesta y desarrollada por Lucía De Leone (2009, p. 117), que instaló en la crítica su lectura del peculiar tratamiento de lo rural en las novelas de la autora. El texto clausura el tópico del aborto y de esa forma instala la difusión del embarazo, hasta entonces un secreto bien guardado de Nefer.

Como si se tratara de un paréntesis que asordina los hechos, el escándalo familiar es precedido por una ceremonia religiosa -la Misión- que exige asistencia perfecta. Ocasión propicia para notar cómo se compaginan los sectores de poder que esta lectura propone como dueños del embarazo de Nefer y de lo que ocurrirá con ella, más allá del arresto de coraje que la llevó a pararse delante de la bruja Borges.

La estanciera, Mercedes, que es además la madrina de Nefer (ese madrinazgo será en el texto un cargo activo) es una figura muy interesante, encabalgada entre el poder que da la tierra y el que promete el cielo. Se preocupa por la delgadez de Nefer. Gallardo la define a partir de su protagonista, que sabe con quién trata: "no tiene ojos para esta gente. No tiene oídos para estas frases. Frases de bosta son, frases de nada" (2018, p. 67). La iglesia es, fuera de toda duda, uno de los policías señalados por Nefer, quien en el trance de un paso difícil por el confesionario omite mencionar su embarazo. Esa elusión está lejos de liberarla, y aquí puede verse que la Misión expone también, junto a las certezas de los poderosos, las ambigüedades del pensamiento de Nefer, en quien conviven la preocupación porque "no sabe cómo acabar con este miedo que come su comida y duerme su sueño" (2018, p. 56), y la inquietud porque, habiéndole ocultado información al sacerdote, participar de la comunión la coloca en la situación de "pecado mortal", algo que verdaderamente la afecta. Como joven feligresa, reclutada sin opciones, Nefer sabe que si comulga, peca, y si no lo hace, señala un pecado anterior. En eso está cuando repara en que ha llegado el Negro, que se encuentra "apoyado en el fondo con los otros hombres. Cuando vuelve a mirar el altar siente la nuca de piedra y el corazón golpeándole la garganta" (2018, p. 60). 
En este episodio religioso, la condición difusa de la ideología de Nefer se va aclarando al lector: Nefer no es solo la amazona valiente y solitaria que llega hasta el borde de obtener el aborto que tanto necesita. También es permeable a la palabra de la Iglesia, que tiende a disuadirla y su tozudo amor por el Negro la distrae de sus problemas sin brindarle soluciones. Congoja es lo que siente en la vuelta a casa. Toda una versión de los perennes desafío y lamento con que Josefina Ludmer (2000) caracterizó a la gauchesca, y entonces, por qué no, también a estos textos que saben derivar de ella.

Allí las cosas tomarán otro cariz y Nefer perderá definitivamente todo control de la situación, que queda en manos de la conjura de al menos tres modos de la punición: la materna, la médica y la terrateniente, todas ellas controladas por la Iglesia católica.

Desde el embarazo, Nefer, que es delgada, viene comiendo poco y nada. Como tantas veces pasa en las familias, de esa pequeñez devendrá la tormenta: "Dije que no quiero! ¡No quiero porque voy a vomitar! ¡Porque voy a tener un chico! Estoy preñada ¡Sí! Y vos podrías haberte dado cuenta si sos tan vieja y sabés tantas cosas" (2018, p. 72). Tras estas palabras, y tras una breve liberación bajo la lluvia, Nefer se repliega en el galpón.

Locura es lo primero que la madre le endilga. Ese calificativo no debería sorprender. Aún aceptando que la madre no sabe todavía que ese embarazo se origina en una violación, como parte de un contexto que no hay que perder de vista, ella computa todo eventual embarazo de sus hijas, mucho más de la que es menor (Nefer es una adolescente, algo que el desarrollo de tareas camperas apenas disimula) como una locura porque va en contra de la moral de la familia, que no es otra que la moral de la estancia, en tanto unidad productiva a cuyo estrato inferior Nefer y familia deben su subsistencia. $\mathrm{Ni}$ que hablar de los preceptos religiosos ante los que todo ese universo se inclina.

De manera que cuando Doña María decreta la locura de su hija mientras la amonesta en ese galpón barrido por el viento, más allá de que considere que peligra su fuente de trabajo, traduce así a su mundo que Nefer ha desafiado, declarando su embarazo en alta voz, todas las relaciones de poder (Foucault, 1989, p. 23) que operan en el poblado y los que lo rodean, todos ellos subsidiarios de la estancia.

La primera de estas relaciones de poder que operan sobre Néfer es la que tiene a la misma Doña María en el polo dominante. La severa matrona conduce a sus hijas con rienda corta. Ella cree que Nefer ha salido de su redil por el embarazo. Es incapaz de pensar que esta salida ocurre porque desarrolla un pensamiento independiente sobre su vida. También se comporta así con el padre de las chicas, al punto de que, si este es el personaje que parece mostrar empatía con Nefer, su voluntad atenuada no permite que eso se descifre cabalmente.

Aún después de tratar a Nefer de loca y canalla, Doña María no termina de creer en su embarazo. La palabra de la subalterna viaja a merced del viento para los oídos del personaje poderoso. Será el poder del médico, en un alarde prefoucaltiano notable, el que ratifique la palabra de Nefer.

En la zona del tablero en que Nefer ha caído, la posibilidad del aborto ni se considera, por lo que ella debe viajar al pueblo con su madre solo para que su condición pueda ser comprobada. Este médico 
no hará nada por ella. Gallardo no lo dice pero es posible que el personaje se haya arrepentido de haber retrocedido cuando la bruja Borges inquirió los motivos de su visita. Dirá su madrina que "abortar...era peor que un crimen, porque es matar a uno que no puede defenderse”. Frases de bosta, diría Nefer.

Como sea, es demasiado tarde. Nefer ya está en manos de los círculos del poder de esas tierras feroces. Aquello que contra toda ley pasó una no tan lejana noche de verano, será resuelto de acuerdo con los criterios de esta gente, que operan como un procedimiento que complementa la violación. Aval familiar, médico, patronal y religioso del crimen inicial.

Habrá que volver - no falta mucho para que la dueña de la estancia dé una "solución" al "problema" a la mencionada frase de Nefer: "los patrones y los policías tienen ideas parecidas" (2018, p. 91)-. Se trata del centro ideológico del texto, ínfima narración que explica quiénes ahogan el deseo de Nefer. Pero también es remarcable cómo Gallardo pone en boca de su protagonista, cuya vida transcurre entre usos y costumbres rurales, un concepto complejo de las ciencias sociales, una hipótesis social. Si bien no es poco lo que contribuye a lograr esta síntesis, que esté antecedido por este otro sintagma: "Las cosas escondidas no pueden hacerse de acuerdo con los patrones porque ellos no comprenden" (2018, p. 91), vinculado decisivamente a un pensamiento despojado de toda marca citadina, la frase lapidaria de Gallardo se vuelve el punto de unión entre su celebrado registro campero y la prosa política, entre sus numerosos apellidos patricios y una forma de marxismo práctico. Las ideas que pronto encuentra parecidas.

El médico está en el pueblo, lo que desde el vamos contribuye a dotarlo de cierto matiz ajeno para los ojos tan campo afuera de Nefer. Comenzada la consulta, en todo momento el profesional se dirige a su madre. Nefer es apenas una muestra sujeta a constatación. La situación aglutina dos disvalores sobre la figura de Nefer: la visita al médico por la desconfianza de su madre que no cree en el embarazo y el castigo cuando su situación se corrobora. Nefer se cubre de ensoñaciones rurales de resonancias previas a sus problemas del presente (y propicias para la prosa de Gallardo) cuando el médico "va hacia un autoclave y saca un guante de goma que empieza a calzarse" (2018, p. 81).

"Mañana acabamos con todo, ya vas a ver" (2018, p. 83), dice la madre, ya de salida, y aunque suena amenazante el lector no puede menos que pensar que Doña María va a poner manos a la obra para gestionar un aborto rápido. Esto solo confirma que el lector, en esos mundos de estancias, puestos y alambrados que Gallardo articula, sería un forastero. Por empezar, Nefer saca pecho con un decidido “conmigo no se va a meter nadie" (2018, p. 82), que es más una declaración de independencia que una voluntad expresa de seguir con el embarazo. Doña María contesta con una ruda exquisitez -si vale el oxímoron- de la mejor coloquialidad de Gallardo: “-Buena estúpida” (2018, p. 83). Da la impresión de que una típica discusión entre una adolescente y su madre se sobreimprime al verdadero problema. Pero ¿existe la adolescencia en ese mundo? ¿Cuánto media entre los últimos vestigios de la infancia de Nefer y el ataque sexual que sufre?

Nefer siente en esos momentos el único tiempo de fugaz comunión con su embarazo: "El que la atormentaba se ha vuelto su amigo (...) en su cuerpo la sangre cobra fluidez, la boca se le enternece. Ya no está sola” (2018, p. 83). 
Desecha rápidamente esa sensación -"amigo secreto no hay ninguno. Semilla triste que crece y crece sin piedad es lo que lleva, no amigo secreto" (2018, p. 86)-, pero eso permite volver sobre el carácter inacabado de la decisión de Nefer respecto de su aborto, la zona del texto que hoy cuesta leer sin caer en anacronismos, sin olvidar por momentos que el drama de Nefer ocurre a mediados del siglo veinte. Por otro lado, de manera indiscutible su discurso refrenda la soledad de la joven violada, embarazada y sin apoyo de la familia. Es que el de Nefer, por más que las miradas hagan foco en su vientre, es el único pensamiento crítico del texto.

El argumento desemboca en una solución terrible. Capitaneadas por la estanciera Mercedes, los impugnadores del embarazo arreglan de manera inconsulta su casamiento con Nicolás, el violador, y la mudanza de los así casados al pueblo.

Cuando los hechos se le vienen encima, Nefer no reconoce la voz de su atacante. Sintomáticamente piensa que se trata de otro, no de un enemigo al que casi no conoce, pero piensa sí, en factores de poder, en quienes toman el control de su vida, y le preparan una suerte de violación cívica: "una voz nueva dice, gruesa de tabaco: -Estás chimeneas son las mejores, tienen un tiraje... si me permite voy a mirarla... No conoce esa voz. ¿Será el médico? El cura no es” (2018, p. 93).

El violador pide disculpas torpes e imposibles, pretende ampararse en el vino bebido en exceso aquella vez. Sus palabras deberían haberse escuchado como confesión en sede judicial. Otro costado que las relaciones de poder del lugar suplantan. Como quiera que sea, queda claro que también él es empujado a formar pareja. Tal vez fue allí donde una eventual denuncia operó como carta decisiva en la manga de Doña Mercedes y Doña María. Los patrones y los policías tienen ideas parecidas.

El viaje en tren de la "pareja" preludia su casamiento arreglado. Para Nefer, el naufragio es total e irreversible.

Con la aparición de Enero en aquel 1958, tal como se bosquejó al comienzo del trabajo, Sara Gallardo lesionó la visión idílica que cierta literatura canónica ofrecía del campo argentino, en la que generaciones de lectores y lectoras fueron formados. Ella narró la pampa como una inmensidad hostil; una hostilidad que no se restringió al territorio sino que se hizo extensiva a los turbios personajes que la pueblan y a las relaciones que entre ellos se establecen. No se puede dejar de pensar en esta fuerte diferenciación que Gallardo introduce, y que en Enero se establece como prerrogativa de comienzo, para explicar tanto su pretérito ninguneo como su enérgico y celebrado regreso desde hace ya una decena de años a otro campo abundante en conflictos: el de la literatura argentina.

\section{Referencias bibliográficas}

Aczel, I. (2020). Literatura Argentina y Aborto: intervención inicial sobre un corpus embrionario. Villa María, Eduvim.

Aira, C. (1993). E1 Monstruo. Paradoxa, 7, 55-71. 
Amícola, J. (2013). Cuerpo, clase y destino en Enero de Sara Gallardo. En Bertúa, P. y De Leone, L. (comps.), Escrito en el viento: lecturas sobre Sara Gallardo (pp. 47-60). Buenos Aires, Eufyl.

De Leone, L. (2009). Otra vuelta. Sara Gallardo y las novelas rurales. Cuadernos del Sur, 39, 107-126.

Deleuze, G. y Guatarri, F. (2006). Mil Mesetas. Capitalismo y esquizofrenia. Valencia, Pre-textos.

Foucault, M. (1989). El poder: cuatro conferencias. México, UAM.

Gallardo, S. (2018). Enero. Buenos Aires, Fiordo.

Gramsci, A. (1977). Quaderni dei carcere. Turín, Einaudi.

Laera, A. (2018). Sin dios ni ley: Nefer, la personaje de Sara Gallardo. Transas, Letras y Artes de América Latina. https://bit.ly/3BNoWAS.

Ludmer, J. (2000). El género gauchesco. Un tratado sobre la patria. Buenos Aires, Perfil.

Pauls, A. (2004). El factor Borges. Barcelona, Anagrama.

Piglia, R. (2014). Formas breves. Barcelona, Debolsillo.

* Marcelo Méndez es Licenciado en Letras por la Universidad de Buenos Aires, en cuya Facultad de Filosofía y Letras da clases en la cátedra de Literatura Argentina del Siglo XX. Ha publicado artículos en diversas publicaciones académicas y concurrió a numerosos congresos de la disciplina. Este trabajo surge en el marco de un proyecto sobre literatura y feminismo dirigido por la Dra. Tania Diz.

RECIBIDO: $11 / 11 / 2020$

ACEPTADO: 04/08/2021 